\title{
Searching for the functional locus of the SNARC effect: Evidence for a response-related origin
}

\author{
INGE M. KEUS and WOLF SCHWARZ \\ University of Nijmegen, Nijmegen, The Netherlands
}

\begin{abstract}
Dehaene, Bossini, and Giraux (1993) showed that when participants make parity judgments, responses to numerically small numbers are made faster with the left hand, whereas responses to large numbers are made faster with the right hand (the SNARC [spatial-numerical association of response codes] effect). According to one view, the SNARC effect arises at an early processing stage due to (in)congruencies between the digit's side of presentation and its representation on the mental number line, independently of response effector(s). Alternatively, the SNARC effect might arise at a later response-related stage due to (in)congruencies between the digit's representation on the mental number line and the side of response, independently of the side of presentation. The results of three experiments, using central and lateralized stimuli, and vocal and manual responses, clearly support the view that the SNARC effect arises at a relatively late response-related stage, without substantive contributions from earlier processing stages.
\end{abstract}

In recent years, the spatial-numerical association of response codes (the SNARC effect) has become an important research tool to explore the cognitive processes that underlie human number comprehension. This effect was first reported by Dehaene, Bossini, and Giraux (1993), who presented participants with the digits $0-9$ and asked them to indicate the parity (odd vs. even) of these digits using manual responses (buttonpresses with the left vs. right index finger). Dehaene etal. (1993) found that, independently of the digit's actual parity status, for numerically small numbers (such as 1 or 2) left-hand responses were faster than right-hand responses, whereas for large numbers (such as 8 or 9) right-hand responses were faster than left-hand responses. In a number of follow-up experiments, Dehaene etal. (1993) further explored this effect and found that it was independent of handedness and occurred in a similar way with either digits or number words. Fias, Brysbaert, Geypens, and d'Ydewalle (1996) and Fias (2001) replicated the basic SNARC effect with both digits and number words. They also showed that when participants had to perform an explicitly nonnumerical task, such as phoneme monitoring, a SNARC effect was found with digits (Fias etal., 1996) but not with number words (Fias, 2001).

The SNARC effect with digits suggests that even when numerical magnitude is irrelevant for the task at hand, an internal magnitude representation is nevertheless automatically activated. That is, numerical magnitude differentially modulates left-hand versus right-hand response times (RTs), not unlike in the spatial variants of Stroop-

Correspondence concerning this article should be addressed to I. M. Keus, University of Nijmegen, NICI, Postbus 9104, 6500 HE Nijmegen, The Netherlands (e-mail: i.keus@nici.kun.nl). type experiments, in which the irrelevant spatial location of a written location word interferes with its meaning $(\mathrm{Lu}$ \& Proctor, 1995; MacLeod, 1991; Palef \& Olson, 1975). This internal representation is often conceptualized as a "mental number line" (e.g., Butterworth, 1999, chap. 5; Dehaene, 1997, chap. 3; Restle, 1970; Schwarz \& Ischebeck, 2000) and according to an influential interpretation of the SNARC effect (Bächtold, Baumüller, \& Brugger, 1998; Butterworth, 1999; Dehaene, 1997; Dehaene etal., 1993; Dehaene, Dehaene-Lambertz, \& Cohen, 1998; Fias, 2001; Fias etal., 1996; Fias, Lauwereyns, \& Lammertyn, 2001; Lammertyn, Fias, \& Lauwereyns, 2002), the orientation of this mental number line is ontogenetically determined by the preferred writing system of the participant. More specifically, for cultures with left-to-right writing systems, the mental number line seems to point from left to right with increasing magnitude. In line with this culture-dependent interpretation, Dehaene et al. (1993) found that Iranian participants, accustomed to a right-to-left writing system and with relatively little exposure to Western culture, tended to associate large numbers with the left-hand side and small numbers with the right-hand side of space. Other evidence suggests that the spatial association of individual numbers is not rigid but flexible to a certain degree. For example, Dehaene et al. (1993; see also Fias et al., 1996; Tlauka, 2002) showed that within a number context ranging from 4 to 9 , the digit 5 is responded to faster with the left hand than with the right hand. However, within the context ranging from 0 to 5 , RTs to the digit 5 are faster with the right than with the left hand. This finding suggests a considerable degree of context-sensitive flexibility in how we represent numerically small versus large numbers, or in how we map these representations onto lateralized manual responses. 
Another important question concerns the functional origin(s) of the SNARC effect. Broadly speaking, there are at least two possibilities for this functional locus, which are by no means mutually exclusive (see, e.g., Brysbaert, 1995). The SNARC effect could originate in at least one of two processing stages that seem to be required in tasks in which SNARC effects are typically observed. The first stage is related to the formation of an early mental number representation of the digit presented to the participant. As suggested by the findings reviewed above, numbers have an early space-related internal representation - independent of the actual response eventually given - with (at least in Western cultures) an inherent left-to-right organization. During a subsequent response selection stage, this initial spacerelated representation then needs to be mapped onto the available responses. This later processing stage is related to the ease or efficiency with which, starting from the initial number representation, we can select one of the available responses.

In an attempt to distinguish between these two possible origins, we studied the separate effects of stimulus versus response lateralization. These manipulations are based on the assumption that stimulus-related manipulations, such as the lateralization of digit stimuli, should predominantly influence the time required to form an initial mental number representation, whereas responserelated manipulations, such as the lateralization of the required response, should mainly influence the ease with which an already created number representation can be mapped onto lateralized responses (cf. Dehaene, 1996; Sternberg, 1969). More specifically, if a SNARC effect originates at a relatively early stage of processing (e.g., stimulus identification), one would expect the spatial layout of the stimulus display to modulate the efficiency with which we can establish an early space-related number representation, which is then further processed at subsequent stages. Specifically, SNARC-like effects could arise at this stage if there is either a benefit from the congruency between the side of presentation of the digit and the relative location of the representation of this digit on the mental number line (i.e., small numbers in the left visual field [LVF], large numbers in the right visual field $[\mathrm{RVF}]$ ), and/or a disadvantage from the incongruity between side of presentation and location of the mental representation (i.e., small numbers in the RVF, large numbers in the LVF). In fact, with this interpretation, one would expect to find SNARC-like effects even when the responses themselves are not lateralized since, according to this early-locus conceptualization, the SNARC effect is related to the relative ease with which an initial number representation is formed. Once this representation is created, the duration of all subsequent processing stages (e.g., response selection) should be independent of how long it took to initially represent these numbers.

Alternatively, the SNARC effect could arise at a later response-related processing stage (e.g., response selec- tion or preparation), because it might be more difficult (i.e., time consuming) to select, for example, a righthand response for a small number that is internally associated with the left side of the mental number line. If this hypothesis is true, the following two predictions should hold. First, we would expect the SNARC effect to occur only with lateralized effectors, such as hands and eyes, but not with nonlateralized responses, such as verbal responses. Second, the way in which the stimuli are presented to the participant (e.g., central or lateralized) should not affect the time to translate the initial number representation onto the corresponding response and thus should not induce a separate or additional contribution to the SNARC effect.

As also stated above, these early- and late-locus conceptualizations are in no way mutually exclusive, and it is quite conceivable that functionally separate components of the SNARC effect arise both during an early processing stage (modulated by laterally presented digits) and during a later stage of response translation (modulated by lateralized responses). In this case, it would be important to estimate the relative contribution of these factors and to explore how these contributions could be experimentally manipulated.

At present, the evidence concerning the issues raised above is inconclusive. Following Dehaene et al.'s (1993) original demonstration, several studies have replicated a SNARC effect with centrally presented stimuli and lateralized manual (Fias, 2001; Fias etal., 1996) or saccadic (Schwarz \& Keus, 2004) responses. In the terms used above, these findings imply that a late response-related functional locus certainly contributes to the SNARC effect. On the other hand, these experiments do not in themselves rule out an additional early contribution to the SNARC effect.

The SNARC effect can be considered as a Type 3 ensemble in Kornblum, Hasbroucq, and Osman's (1990) taxonomy of stimulus-response compatibility effects, since the irrelevant magnitude information of the stimulus seems to be mentally represented at the left or right side of space, resulting in dimensional overlap with the (side of the) required response. Another effect that falls into this Type 3 category is the so-called Simon effect, which has been found in numerous studies with both auditory and visual stimuli (Craft \& Simon, 1970; Hedge \& Marsh, 1975; Simon \& Small, 1969; Tlauka, 2002; see Lu \& Proctor, 1995 for a review). In the standard Simon task with visual stimuli, participants have to respond manually to the color of a visual stimulus, which is either presented in the LVF or the RVF. The typical finding is that responses are faster when the side of presentation and the side of response are compatible (compatible trials) than when they are incompatible (incompatible trials). Thus, although the side of presentation of the stimulus is not relevant for the task, it interferes with the processing of the relevant stimulus attribute (i.e., color). Mapelli, Rusconi, and Umiltà (2003) studied the occurrence of the SNARC and Simon effects in a single experiment 
using a parity judgment task with laterally presented stimuli and manual responses. Mapelli et al. found no interaction between the SNARC and Simon effects in their Experiment 1; therefore, they suggested that the effects occur in different stages of processing. Since the Simon effect is widely accepted to be related to the responseselection stage (Lu \& Proctor, 1995; Mapelli etal., 2003; Simon \& Berbaum, 1990; Umiltà \& Nicoletti, 1990; for a different view, see Hasbroucq \& Guiard, 1991), this would suggest that the SNARC effect is related to a processing stage other than response selection. In a second experiment, Mapelli et al. extended their reasoning to the reverse Simon effect (i.e., incompatible trials are faster than compatible trials) and showed that there also was no interaction between the SNARC and reverse Simon effects.

Evidence that can be interpreted as supporting the notion of an early, response-independent component of the SNARC effect comes from two recent studies by Tlauka (2002, Experiment 2) and Fischer, Castel, Dodd, and Pratt (2003). Tlauka asked participants to respond to two numbers (100 and 900) presented in either the LVF or the RVF with their left or right hand, depending on the identity of the digit. In addition to a standard SNARC effect, his results also showed a SNARC-like effect that depended on the side of presentation of the numbers: Responses to LVF presentations were found to be faster for the number 100 than for the number 900, whereas RTs to RVF presentations showed the opposite effect. This effect is reminiscent of the SNARC effect in that the interaction between magnitude and side of presentation also reflects a spatial numerical association. However, the important difference to the standard SNARC effect is that in the SNARC-like case, the association is not in any way related to the response layout (e.g., lateralized or central) but merely to the stimulus layout.

Fischer et al. (2003) used a simple detection task in which participants had to respond to a target by pressing the spacebar with their preferred hand. After they were presented with an initial display of two boxes placed on the left and right of a central fixation cross, the fixation cross was replaced by one of four digits $(1,2,8$, or 9$)$. This digit remained on the screen for $300 \mathrm{msec}$ and was then replaced by the fixation cross again. After an additional random delay, a target (a white circle) appeared in one of the two boxes. Although participants were told that the digits did not predict the location of the target, the magnitude of the digit did modulate detection times in a SNARC-like manner similar to that in Tlauka's (2002) Experiment 2: Targets in the LVF were detected faster when preceded by a small digit ( 1 or 2 ), whereas targets in the RVF were detected faster when preceded by a large digit ( 8 or 9 ).

It should, however, be noted that Tlauka (2002) used a task in which the magnitude of the number presented is directly response relevant, whereas the typical SNARC effect is studied with tasks in which numerical magnitude per se is irrelevant and in which typically a larger range of numbers is mapped onto each of the two re- sponses, whereas Tlauka mapped just one number onto each response. Also, the interaction between side of presentation and numerical magnitude was only obtained in an experiment using the numbers 100 and 900 , but not in a variant using the numbers 1 and 100 . Fischer et al. (2003) used a task in which the numerical magnitude of the digit was irrelevant, but they found SNARC-like effects only when the time for the presentation of the digit $(300 \mathrm{msec})$ plus the random delay lasted $600 \mathrm{msec}$ or more before the target was presented. In addition, Fischer etal.'s imperative stimulus was a white circle, whereas in standard tasks in which the SNARC effect is found, some attribute of the digit (e.g., its parity) itself is the relevant stimulus. Therefore, it would be important to study the effects of lateralizing stimuli in a context that is more reminiscent of the standard SNARC setup, in which the stimuli are digits and one of their attributes is the response-relevant dimension, whereas the magnitudes of these digits are irrelevant for the performance of the task.

The aim of the present experiments was to study the relative importance of chronometrically early and later contributions to the SNARC effect, with the former thought to be linked to the formation of an initial spacerelated mental representation and the latter related to processes of response translation and activation. To this end, we conducted experiments in which participants made speeded parity judgments. As in Dehaene et al.'s (1993) original SNARC study, the presented digits ranged from 0 to 9 , but now they were presented $10^{\circ}$ into either the LVF or the RVF. In Experiment 1, participants had to respond vocally, by naming the digit's parity. We reasoned that vocal responses lack the spatial association implicit in manual responses so that the contribution, if any, of early representational components, thought to be independent of lateralized responses, could be evaluated in isolation. Side of presentation was varied to see whether this would modulate the efficiency of forming a space-related number representation in a SNARC-like manner.

Experiment 2 consisted of four parity-judgment tasks, in which the factors stimulus presentation (central vs. lateralized) and response effector (vocal vs. manual) were orthogonally varied. In this way, we were able to study the effects of lateralizing stimuli for each response effector separately and thereby to compare these effects across effectors.

If the SNARC effect also has an early representational component, we would expect to find a SNARC-like effect as a result of the lateralized stimuli-even with vocal responses. Specifically, we would expect vocal parity judgments to be faster for numerically small numbers presented in the LVF as opposed to the RVF. For numerically large numbers, we would expect faster vocal responses for RVF presentations than for LVF presentations. Also, for Experiment 2, we would expect the SNARC-like effects of lateralization of the stimuli to occur when manual responses are used, in addition to the standard SNARC effect that presumably originates at a 
later stage, during which lateralized responses are activated.

On the other hand, if the SNARC effect exclusively reflects the greater ease with which small (or large) numbers are mapped onto left-hand (or right-hand) effectors, we would expect no effects of lateralizing the stimuli, and thus no SNARC-like effect in Experiment 1. In addition, in Experiment2, we would only expect a standard SNARC effect with lateralized responses, but no additional contribution related to the lateralized stimulus presentation.

\section{EXPERIMENT 1}

\section{Method}

Participants. Sixteen (11 female, 5 male) students at the University of Nijmegen, 19-27 years of age, participated in the experiment. They either received a payment of $€ 5(\approx \$ 5)$ or course credit for their participation.

Stimuli and Apparatus. The stimuli consisted of the digits 0-9, which were presented against a dark background using the true type Verdana font. Each digit was displayed in green on a $75-\mathrm{Hz}, 480 \times$ 640 pixel VGA color monitor; the display timing was synchronized with the video refresh cycle. The digits were presented either $10^{\circ}$ to the left or right of a central fixation cross and were viewed from a distance of approximately $50 \mathrm{~cm}$; they subtended $2.5^{\circ} \times 1.7^{\circ}$. The onset of the vocal responses was registered to the nearest millisecond using an external voice key attached to the computer's parallel port. The type of vocal response (in Dutch, "oneven" or "even") was registered by the experimenter, who sat behind the participant.

Procedure. The task of the participant was to judge the parity status (odd vs. even) of the presented digit. The participants were instructed to name the parity status as quickly and accurately as possible. In the instructions, the definition of "parity" was given and participants were told explicitly which numbers are odd and which are even.

Each trial started with the presentation of a central white fixation cross, on which the participants were instructed to focus their gaze during the entire trial. After $300 \mathrm{msec}$, a single digit was presented to either the left or the right of the fixation cross. Both the digit and fixation cross remained on the screen until a response was given. Vocal RTs were defined as the time from the onset of the digit to the onset of the naming response. The next trial started 1,200-1,400 msec (uniform distribution) later.

A single block contained four practice trials (except for the first block, which contained 10 practice trials), which were followed by 50 regular trials. The trials were generated by the computer in a random order, subject to the boundary condition that within two consecutive blocks, each digit preceded every other digit exactly once. Each digit was presented in each visual half-field equally often (30 times in each half-field in the entire experiment). Between blocks, a break of at least $20 \mathrm{sec}$ could be terminated by the participants pushing a button on a response keyboard. During the break, feedback was given on the screen about the number of blocks done, the number of remaining blocks, the mean RT of the last block, and the mean RT of the fastest block so far. The experiment consisted of 12 blocks (600 regular trials) and took approximately $45 \mathrm{~min}$.

Data analyses. Trials with RTs shorter than $200 \mathrm{msec}$ or longer than $1,200 \mathrm{msec}$ (a total of $0.11 \%$ ) were excluded from all analyses.

Mean RTs were calculated across all correct trials. Two different types of errors were defined: task-related errors such as incorrect or articulative imperfect answers (e.g., "oven"), and nontask-related errors such as premature or delayed triggering (e.g., due to coughs). Error rates were calculated over only the task-related errors.

Mean RTs were subjected to a repeated measures $5 \times 2 \times 2$ analysis of variance (ANOVA), with the three within-subjects fac- tors magnitude bin $(0 / 1,2 / 3,4 / 5,6 / 7$, and $8 / 9$; cf. Dehaene et al., 1993; Schwarz \& Keus, 2004¹), parity (odd vs. even), and side of presentation (LVF vs. RVF).

Error rates were first transformed using the $\arcsin \left(\bigvee_{p}\right)$ transformation (e.g., Bishop, Fienberg, \& Holland, 1975, pp. 367ff.) to achieve approximate variance equality and then subjected to an ANOVA of the same format as that for RTs.

\section{Results}

Response times. Magnitude had a significant main effect on RT $\left[F(4,60)=17.3, M S_{\mathrm{e}}=497.5, p<.001\right]$. RTs to the magnitude bins $0 / 1(561 \mathrm{msec})$ and $8 / 9$ $(547 \mathrm{msec})$ were slower than those to the three intermediate magnitude bins $(537,534$, and $534 \mathrm{msec}$, respectively). There was also a significant main effect of parity $\left[F(1,15)=6.36, M S_{\mathrm{e}}=1,823.2, p=.023\right]$ in that responses to even numbers were slower $(549 \mathrm{msec})$ than those to odd numbers $(537 \mathrm{msec})$. The significant interaction between magnitude and parity $[F(4,60)=7.22$, $\left.M S_{\mathrm{e}}=503.5, p<.001\right]$ showed that this difference in RT between odd and even numbers occurred only with the magnitude bins $0 / 1$ and $6 / 7$; RTs to the digit $0(574 \mathrm{msec})$ were slower than those to the digit $1(548 \mathrm{msec})$, and RTs to the digit $6(550 \mathrm{msec})$ were slower than those to the digit 7 (519 msec).

A marginally significant main effect of side of presentation was found $\left[F(1,15)=4.49, M S_{\mathrm{e}}=590.1, p=\right.$ $.051]$; responses to digits in the $\operatorname{LVF}(546 \mathrm{msec})$ were slightly slower than those to digits in the RVF $(540 \mathrm{msec})$. The interaction between side of presentation and parity was not significant $[F(1,15)=0.03]$.

More central to the purpose of this study was the interaction between magnitude and side of presentation, which was not significant $\left[F(4,60)=0.26, M S_{\mathrm{e}}=358.7\right.$, $p=.901]$. As illustrated in Figure 1A, the difference in RTs between LVF and RVF presentations was the same for each magnitude bin. Also the three-way interaction of magnitude, side of presentation, and parity was not significant $[F(4,60)=0.612, p=.656]$.

Error rates. The overall error rate was $3.42 \%$, of which $2.49 \%$ were task-related errors and $0.93 \%$ were nontask-related errors. The effects reported below refer exclusively to task-related errors. A similar pattern of effects was found with errors as with RTs; therefore, only the effects most relevant for the purpose of this study will be discussed.

The interaction between magnitude and side of presentation was not significant $\left[F(4,60)=0.57, M S_{\mathrm{e}}=\right.$ $0.01, p=.687]$, indicating that for each magnitude bin the difference in the number of errors made with LVF and RVF presentations was the same (see Figure 1B). Also, the three-way interaction of magnitude, side of presentation, and parity was not significant $[F(4,60)=$ $\left.0.828, M S_{\mathrm{e}}=301.7, p=.512\right]$.

\section{Discussion}

The results of Experiment 1 show that, in vocal parity judgments, no SNARC-like interaction effects were found between numerical magnitude and side of presen- 

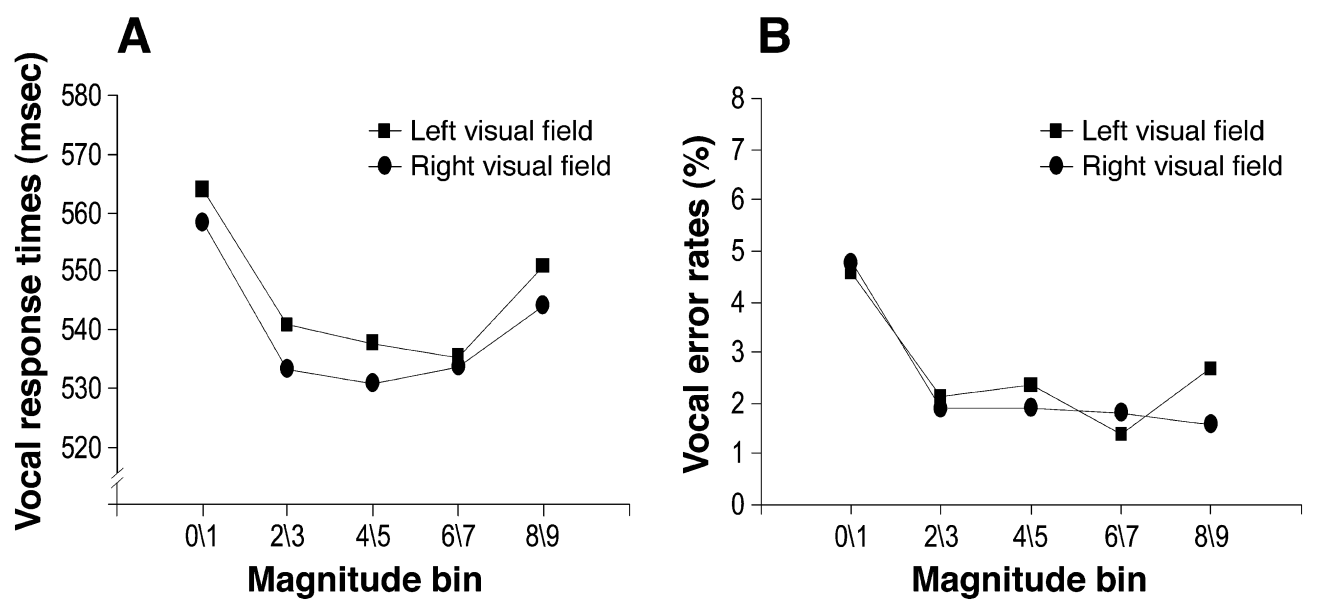

\begin{abstract}
Figure 1. (A) Mean vocal response times in Experiment 1 for left visual field and right visual field presentations as a function of numerical magnitude. (B) Vocal error rates in Experiment 1 for left visual field and right visual field presentations as a function of numerical magnitude.
\end{abstract}

tation, whether on RTs or on error rates. More specifically, the difference in RTs or error rates between digits in the LVF and RVF were the same for each magnitude bin, indicating that the effects of magnitude and side of presentation are additive. In other words, numerical magnitude does not modulate the effect of side of presentation.

The absence of SNARC-like effects with lateralized stimuli and vocal responses seems to argue against the view that the SNARC effect, as found by Dehaene etal. (1993), originates at least in part at a relatively early stage of processing. After all, according to the early-locus view, SNARC-like effects should have occurred independently of the effector used to respond. Rather, the results seem to suggest that the locus of the SNARC effect is only at a later stage of processing, given that SNARC effects do occur with lateralized responses and central stimuli (Dehaene etal., 1993; Fias, 2001; Fias etal., 1996; Schwarz \& Keus, 2004). On the other hand, the findings above contrast with the results of Tlauka's (2002) Experiment2, which yielded an interaction between numerical magnitude and side of presentation. However, it should be noted that this interaction was not found in Tlauka's Experiment 1, that his task was not parity judgment but target identification, and that, instead of using vocal responses, his participants were required to use manual responses. Thus, one explanation for our results could be that the SNARC effect does not originate at an early processing stage, but only at a later response- related processing stage. This, in turn, would suggest that the SNARC-like findings of Tlauka are attributable to differences between our task and that of Tlauka.

Another potential explanation for our results could be that there might actually be an interaction between magnitude and side of presentation, but the power of our experiment was too low to find this interaction effect to be significant. To evaluate this interpretation, we estimated the statistical power of the magnitude $\times$ side of presen- tation interaction by the methods described by Cohen (1995). The index of the empirical size of the interaction effect that we found was only .05 , which is half of what Cohen calls a small effect size $(f=.10)$; correspondingly, the power to detect this small effect was also very small - namely, .06. However, had the effect been medium $(f=.25)$ or large $(f=.40$ or .50$)$, power would have been higher $(.31, .70$, and .89 , respectively), and the interaction would have been less likely to go undetected.

In summary, the results of Experiment 1 do not show a SNARC-like effect between magnitude and side of presentation. To distinguish between the two possible explanations for the absence of this interaction and to get more conclusive evidence about the locus of the SNARC effect, we conducted a second experiment, which consisted of four subexperiments, all with a parity-judgment task.

To address the problem of low statistical power in the first experiment, we replicated Experiment 1 to see whether we would replicate the additive effects of magnitude and side of presentation. As a second subexperiment, we replicated Dehaene etal.'s (1993) basic SNARC experiment by using central stimuli and manual responses.

Tlauka (2002) had found an interaction between magnitude and side of presentation in a task involving manual responses. To match for this difference in effectors between our experiment and his, the second subexperiment was an extension of Experiment 1 in which we used manual responses instead of vocal ones. A further advantage of this setup was that we were able to study both the interaction between numerical magnitude and visual field (i.e., the SNARC-like effect) and the interaction between magnitude and response (i.e., the standard SNARC effect) at the same time. Note that this is a replication of Mapelli etal.'s (2003) task, although they did not study the interaction between numerical magnitude and side of presentation.

The fourth subexperiment was done by using central stimuli and vocal responses. In this way, all four possi- 
ble combinations of stimulus presentation (central vs. lateralized) and effector (vocal vs. manual) were studied.

\section{EXPERIMENT 2}

\section{Method}

The experiment consisted of four subexperiments - namely, all combinations of the factors stimulus presentation (central vs. lateralized) and effector (vocal vs. manual). This resulted in central vocal, lateralized vocal, central manual, and lateralized manual tasks.

\section{Participants}

Twenty-four ( 21 female, 3 male) right-handed students at the University of Nijmegen, 19-27 years of age, participated in two sessions of the experiment in return for a payment of $€ 15(\approx \$ 15)$ or course credit. None had participated in Experiment 1.

\section{Stimuli and Apparatus}

The stimuli and apparatus for the (central and lateralized) vocal tasks were as in Experiment 1, except that for the central vocal task, digits were presented centrally (i.e., replacing the fixation cross in the middle of the screen) instead of $10^{\circ}$ to the left or right of the central fixation cross.

For the manual tasks, the stimuli were as in the vocal tasks; digits were presented centrally in the central manual task and presented $10^{\circ}$ to the left or right of a central fixation cross in the lateralized manual task. The apparatuses for the manual task were as in Experiment 1, except that now RTs were recorded using an external response keyboard attached to the computer's parallel port.

\section{Procedure}

In all four tasks, the participants had to judge the parity status (odd vs. even) of the presented digits - in the vocal tasks, by naming the parity and in the manual tasks, by making buttonpresses. They were instructed to be as fast and accurate as possible. In the instructions, the definition of parity was given and participants were told explicitly which numbers are odd and which are even.

For the vocal tasks, RTs were defined as the time from the onset of the digit to the onset of the naming response. For the manual tasks, RTs were defined as the time from the onset of the digit to the onset of the buttonpress.

The participants performed two different sessions on two separate days. In each session, they started with one of the manual tasks, followed by a vocal task, and they finished with the other manual task. In each session, the participants worked under the same mapping of parity to response hand for both manual tasks. The order of manual task (central first vs. lateralized first), order of vocal task (central in first session vs. lateralized in first session), and order of mapping (even-left in first session vs. even-right in first session) were all counterbalanced across participants. Each session took approximately $75 \mathrm{~min}$.

Central vocal task. Trials were built up in the same way as in Experiment 1 except that digits now replaced the fixation cross and thus were presented centrally. Blocks were also built up in the same way as in Experiment 1, but now the task consisted of only six blocks, resulting in a total of 300 trials.

Lateralized vocal task. Trials and blocks were built up in exactly the same way as in Experiment 1 but the task consisted of only six blocks, resulting in a total of 300 trials. Side of presentation of the digit (LVF vs. RVF) was systematically varied in such a way that each digit was presented in each visual half-field equally often (15 times in each half-field). As an additional instruction, the participants were instructed to focus their gaze on the fixation cross during the entire trial.

Central manual task. Trials and blocks were built up in the same way as in the central vocal task, but the manual task consisted of 12 blocks, resulting in a total of 600 trials. In addition to the feedback that was given in the vocal tasks, feedback was now given for incorrect trials by presenting the word "error" for $2 \mathrm{sec}$. Between blocks, extra feedback was given concerning the number of errors in the last block. In the even-left mapping, the participants pressed the left button of the button box with their left index finger when the digit was even and the right button with their right index finger when the digit was odd. In the even-right mapping, this mapping of parity onto response hand was reversed.

Lateralized manual task. Trials and blocks were built up in the same way as in the central manual task, except that the stimuli were presented left or right of the fixation cross. Side of presentation of the digit (LVF vs. RVF) was systematically varied in such a way that each digit was presented in each visual half-field equally often (30 times in each half-field). As in the central manual task, the participants worked under one mapping of parity to response hand in each session. In addition, the participants were instructed to focus their gaze on the fixation cross during the entire trial.

During the entire experiment, the experimenter sat behind the participant to note the responses given during the vocal tasks.

Data analyses. For all tasks, trials with RTs shorter than $200 \mathrm{msec}$ or longer than $1,200 \mathrm{msec}(0.5 \%$ for the central vocal task, $1.15 \%$ for the lateralized vocal task, $0.28 \%$ for the central manual task, and $0.5 \%$ for the lateralized manual task) were excluded from all analyses.

Per task, mean RTs were calculated across all correct trials. As in Experiment 1, two different types of errors were defined for the vocal tasks: task-related errors and nontask-related errors. Per vocal task, error rates were calculated over only the task-related errors. For each manual task, error rates included all erroneous trials.

Central vocal task. Mean RTs were subjected to a repeated measures $5 \times 2$ ANOVA with the two within-subjects factors magnitude bin $(0 / 1,2 / 3,4 / 5,6 / 7$, or $8 / 9)$ and parity (odd vs. even).

Lateralized vocal task. Mean RTs were subjected to a repeated measures $5 \times 2 \times 2$ ANOVA with the three within-subjects factors magnitude bin, parity, and side of presentation (LVF vs. RVF).

Central manual task. Mean RTs were subjected to a repeated measures $5 \times 2 \times 2$ ANOVA with the three within-subjects factors magnitude bin, parity, and response hand (left vs. right).

Lateralized manual task. Mean RTs were subjected to a repeated measures $5 \times 2 \times 2 \times 2$ ANOVA with the four within-subjects factors magnitude bin, parity, side of presentation, and response hand.

For each task, error rates were transformed as in Experiment 1 and then subjected to an ANOVA of the same format as that for the corresponding RT.

Comparisons between tasks. To study the overall effects of lateralizing stimuli and response effectors, per magnitude bin a single mean was calculated for each participant in each condition. On these means, a $5 \times 2 \times 2$ repeated measures ANOVA was performed with magnitude bin, stimulus presentation (central vs. lateralized), and effector (vocal vs. manual) as within-subjects factors.

\section{Results}

\section{Central Vocal Task}

Response times. A significant main effect of numerical magnitude was found $\left[F(4,92)=15.1, M S_{\mathrm{e}}=362.7\right.$, $p<.001]$; responses to the magnitude bin $0 / 1$ (544 msec) were slower than those to the four other magnitude bins (518-524 msec). No main effect of parity was found $[F(1,23)=0.41]$, but there was a significant interaction between magnitude and parity $\left[F(4,92)=4.68, M S_{\mathrm{e}}=\right.$ $402.7, p=.002]$; for the magnitude bins $0 / 1$ and $6 / 7$, RTs were slower for the even numbers, whereas for the magnitude bin $8 / 9$, RTs were slower for the odd numbers.

Error rates. The overall error rate was $1.95 \%$, of which $1.35 \%$ were task-related errors and $0.6 \%$ were nontask-related errors. Neither numerical magnitude nor 
parity had significant effects on error rates $[F(4,92)=2.0$, $M S_{\mathrm{e}}=0.009, p=.10$; and $F(1,23)=1.02, M S_{\mathrm{e}}=0.01, p=$ .32 , respectively], but an interaction between magnitude and parity was found $\left[F(4,92)=3.524, M S_{\mathrm{e}}=0.008, p=\right.$ .01 ]; for the magnitude bins $0 / 1$ and $2 / 3$, more errors were made with the even numbers, whereas for the magnitude bin $8 / 9$, more errors were made with the odd numbers.

\section{Lateralized Vocal Task}

Response times. There was a significant main effect of numerical magnitude $\left[F(4,92)=12.14, M S_{\mathrm{e}}=675.5, p<\right.$ $.001]$; responses to the magnitude bins $0 / 1(571 \mathrm{msec})$ and $8 / 9(562 \mathrm{msec})$ were relatively slow in comparison with those to the three intermediate bins $(550,551$, and $552 \mathrm{msec}$, respectively). Neither parity, nor side of presentation, nor their interaction had significant effects on RT $\left[F(1,23)=1.42, M S_{\mathrm{e}}=1,699.1, p=.246 ; F(1,23)=2.47\right.$, $M S_{\mathrm{e}}=725.6, p=.129$; and $F(1,23)=2.1, M S_{\mathrm{e}}=423.6$, $p=.161$, respectively]. The interaction between magnitude and parity was found to be significant $[F(4,92)=6.89$, $\left.M S_{\mathrm{e}}=785.6, p<.001\right]$; for the magnitude bins $0 / 1$ and $6 / 7$, responses to odd numbers were faster, whereas for the magnitude bins $2 / 3$ and $4 / 5$, responses to even numbers were faster.

As in Experiment 1, the interaction between magnitude and side of presentation was not significant $[F(4,92)=$ $\left.1.85, M S_{\mathrm{e}}=514.0, p=.127\right]$ : The difference of naming latencies between LVF and RVF presentations is not significantly different across the magnitude bins (see Figure 2A). Also, the three-way interaction of magnitude, side of presentation, and parity was not significant $\left[F(4,92)=0.37, M S_{\mathrm{e}}=588.9, p=.828\right]$.

Error rates. The overall error rate was $2.47 \%$, of which $1.62 \%$ were task-related errors and $0.85 \%$ were nontask-related errors. A similar pattern of effects was found with errors as was found with RTs, except that the interaction between magnitude and parity was not significant $\left[F(4,92)=2.03, M S_{\mathrm{e}}=0.011, p=.096\right]$. Most important for our purposes, the interaction between magnitude and side of presentation was not significant $\left[F(4,92)=0.36, M S_{\mathrm{e}}=0.012, p=.835\right.$; see Figure 2B $]$, nor was the three-way interaction among magnitude, side of presentation, and parity $\left[F(4,92)=1.17, M S_{\mathrm{e}}=\right.$ $0.015, p=.329]$.

\section{Central Manual Task}

Response times. A significant main effect of numerical magnitude was found $\left[F(4,92)=12.21, M S_{\mathrm{e}}=548.2\right.$, $p<.001$ ]; responses to the magnitude bin $0 / 1$ ( $476 \mathrm{msec})$ were relatively slow in comparison with those to the other magnitude bins (454-463 msec). Neither parity, nor response hand, nor their interaction had significant effects on RT $\left[F(1,23)=0.28\left[F(1,23)=2.39, M S_{\mathrm{e}}=944.4, p=\right.\right.$ .136 ; and $F(1,23)=1.23, M S_{\mathrm{e}}=11,836.5, p=.28$, respectively]. An interaction between magnitude and parity was found $\left[F(4,92)=11.8, M S_{\mathrm{e}}=803.1, p<.001\right]$, mainly due to faster responses to the digit $7(447 \mathrm{msec})$ than to the digit $6(470 \mathrm{msec})$ and faster responses to the digit $8(447 \mathrm{msec})$ than to the digit $9(479 \mathrm{msec})$.

More important to our purposes, a significant SNARC effect was found $\left[F(4,92)=14.52, M S_{\mathrm{e}}=686.8, p<\right.$ $.001]$. As can be seen in Figure $3 \mathrm{~A}$, the difference between right-hand responses and left-hand responses decreases as magnitude increases. More specifically, with small magnitudes left-hand responses tend to be faster, whereas with large magnitudes right-hand responses tend to be faster. Also, a significant three-way interaction with parity was found $\left[F(4,92)=3.54, M S_{\mathrm{e}}=\right.$ $332.31, p=.01]$, due to a more pronounced SNARC effect with even numbers.

Error rates. The overall error rate was $1.86 \%$. A significant main effect of magnitude was found $[F(4,92)=$


Figure 2. (A) Mean vocal response times in the lateralized vocal task of Experiment 2 for left visual field and right visual field presentations as a function of numerical magnitude. (B) Vocal error rates in the lateralized vocal task of Experiment 2 for left visual field and right visual field presentations as a function of numerical magnitude. 

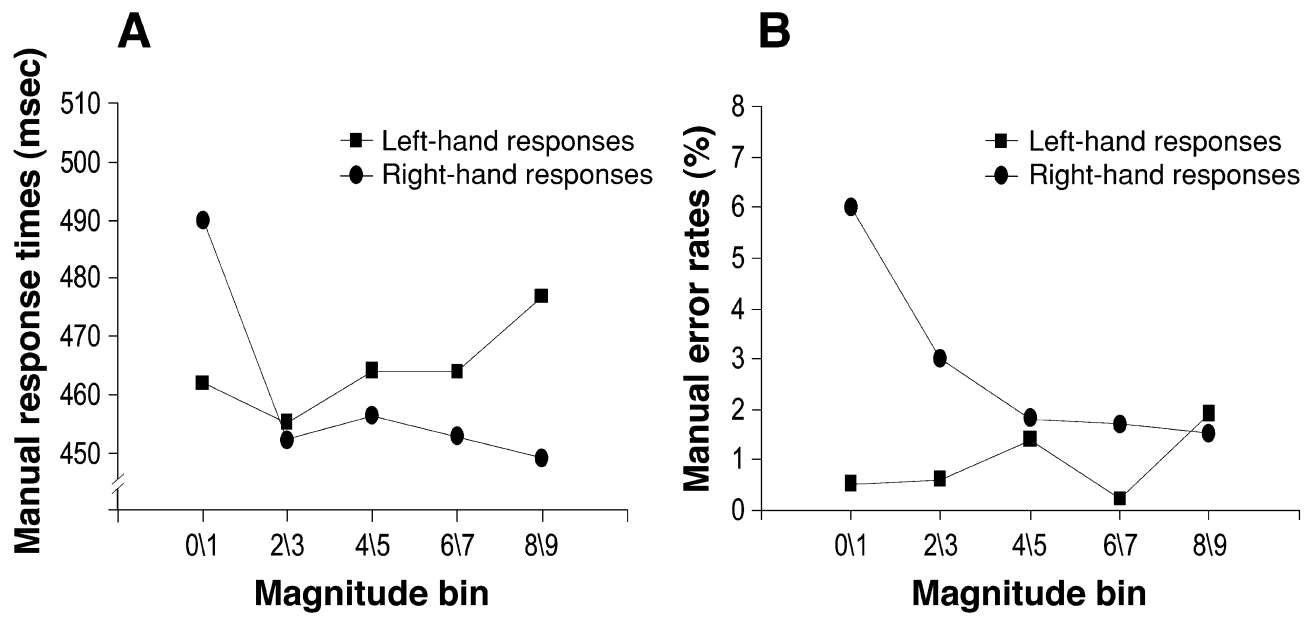

\begin{abstract}
Figure 3. (A) Mean manual response times in the central manual task of Experiment 2 for left-hand responses and right-hand responses as a function of numerical magnitude. (B) Manual error rates in the central manual task of Experiment 2 for left-hand responses and right-hand responses as a function of numerical magnitude.
\end{abstract}

4.93, $\left.M S_{\mathrm{e}}=0.010, p=.001\right]$; more errors were made with the magnitude bin $0 / 1(3.2 \%)$ than with the other magnitude bins $(1.0 \%-1.8 \%)$. Both parity and response hand had a significant main effect on error rates $[F(1,23)=29.18$, $M S_{\mathrm{e}}=0.008, p<.001 ; F(1,23)=31.92, M S_{\mathrm{e}}=0.021, p<$ .001 , respectively]. More errors were made with odd numbers and with right-hand responses. ${ }^{2}$ The difference in errors between left- and right-hand responses was larger for odd numbers than for even numbers $[F(1,23)=$ $7.092, M S_{\mathrm{e}}=0.014, p=.014$, for the interaction parity $\times$ side of presentation]. The interaction between magnitude and parity was also significant $\left[F(4,92)=4.86, M S_{\mathrm{e}}=\right.$ $0.009, p=.001]$. Responses to odd numbers were more error prone for the magnitude bins $0 / 1,4 / 5$, and $8 / 9$, whereas there was no difference for the other magnitude bins.

A SNARC effect was also found $[F(4,92)=12.65$, $\left.M S_{\mathrm{e}}=0.008, p<.001\right]$. As can be seen in Figure 3B, the difference between error rates with right-hand responses minus error rates with left-hand responses decreases with increasing magnitude; the pattern forms a funnel interaction, because on average more errors were made with right-hand responses than with left-hand responses. The three-way interaction with parity was not significant $[F(4,92)=1.0]$

\section{Lateralized Manual Task}

Response times. Numerical magnitude had a significant main effect on RT $\left[F(4,92)=10.36, M S_{\mathrm{e}}=1,353.9\right.$, $p<.001]$; RTs to the magnitude bins $0 / 1(517 \mathrm{msec})$ and $8 / 9(519 \mathrm{msec})$ were slower than those to the three intermediate bins (500-504 msec). No main effects were found for parity or response hand (all $p \mathrm{~s}>.05$ ), but there was a significant main effect of side of presentation $\left[F(1,23)=6.332, M S_{\mathrm{e}}=1,397.9, p=.019\right]$ as a result of faster responses to LVF presentations. The interaction of parity $\times$ side of presentation was also significant
$\left[F(1,23)=6.9, M S_{\mathrm{e}}=1,569.7, p=.015\right]$, showing that the difference between LVF and RVF presentations existed only for even numbers. A significant interaction between magnitude and parity was found $[F(4,92)=$ $\left.12.5, M S_{\mathrm{e}}=1,460.8, p<.001\right]$, mainly due to faster responses to the digit $7(487 \mathrm{msec})$ than to the digit 6 $(513 \mathrm{msec})$ and faster responses to the digit $8(506 \mathrm{msec})$ than to the digit $9(533 \mathrm{msec})$.

The interaction between magnitude and side of presentation was not significant $\left[F(4,92)=1.57, M S_{\mathrm{e}}=948.4\right.$, $p=.190]$; as can be seen in Figure 4A, the difference between LVF and RVF presentations is not modulated by numerical magnitude. Also, the three-way interaction among magnitude, side of presentation, and parity was not significant $\left[F(4,92)=0.528, M S_{\mathrm{e}}=600.6, p=.715\right]$.

As for the interaction between magnitude and response hand, the SNARC effect was significant $[F(4,92)=5.146$, $\left.M S_{\mathrm{e}}=1,141.7, p=.001\right]$; as can be seen in Figure 5A, the difference between right-hand responses and lefthand responses decreases as magnitude increases.

The interaction between side of presentation and response hand was significant $\left[F(1,23)=11.04, M S_{\mathrm{e}}=\right.$ $2,771.3, p=.003]$. Left-hand responses were faster to stimuli in the $\operatorname{RVF}(503 \mathrm{msec})$ than to stimuli in the $\operatorname{LVF}(520 \mathrm{msec})$, whereas right-hand responses were faster to LVF presentations $(503 \mathrm{msec})$ than to RVF presentations ( $509 \mathrm{msec}$; see Figure 6A). In other words, a reverse Simon effect was found, showing that trials in which the presentation side and response side were incompatible were faster than those in which they were compatible.

All other two-, three-, and four-way interactions did not reach significance.

Error rates. The overall error rate was $2.9 \%$. The only significant main effect found was the effect of magnitude $\left[F(4,92)=2.728, M S_{\mathrm{e}}=0.016, p=.034\right]$. More errors were made with the magnitude bins $0 / 1(3.5 \%)$ and $8 / 9(3.7 \%)$ than with the three intermediate bins 

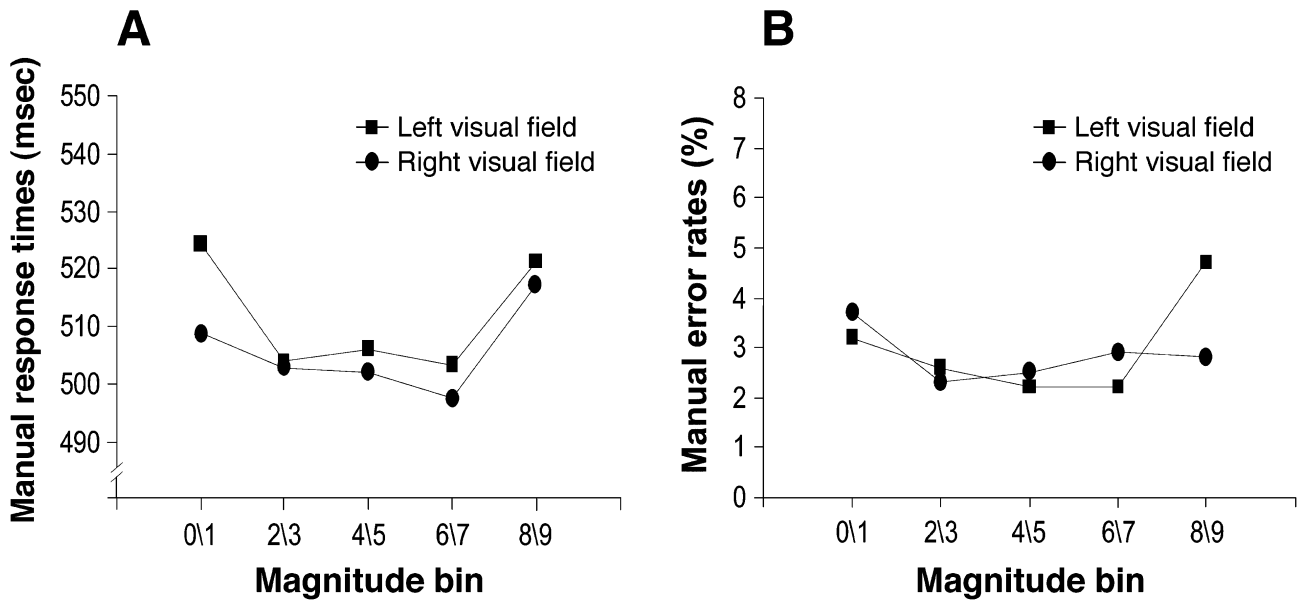

Figure 4. (A) Mean manual response times in the lateralized manual task of Experiment 2 for left visual field and right visual field presentations as a function of numerical magnitude. (B) Manual error rates in the lateralized manual task of Experiment 2 for left visual field and right visual field presentations as a function of numerical magnitude.

$(2.4 \%-2.6 \%)$. The interaction between parity and response hand was significant $\left[F(1,23)=6.209, M S_{\mathrm{e}}=\right.$ $0.016, p=.02]$; for even numbers, there were no differences between left- and right-hand responses, but for odd numbers more errors were made with right-hand responses. The interaction between magnitude and parity was significant $\left[F(4,92)=7.4, M S_{\mathrm{e}}=0.02, p<.001\right]$; for the magnitude bins $0 / 1,2 / 3$, and $6 / 7$, more errors were made with even numbers, whereas for the other magnitude bins, more errors were made with odd numbers.

Similar to the findings with RT, the interaction between magnitude and side of presentation was not significant for error rates $\left[F(4,92)=1.82, M S_{\mathrm{e}}=0.018, p=\right.$ .133 ; see also Figure 4B], nor was the three-way inter- action among magnitude, side of presentation, and parity $\left[F(4,92)=0.201, M S_{\mathrm{e}}=0.02, p=.937\right]$.

As was found for RT, the SNARC effect on error rates was significant $\left[F(4,92)=3.84, M S_{\mathrm{e}}=0.017, p=.006\right]$; as can be seen in Figure 5B, the difference in errors between right-hand minus left-hand responses decreased with increasing magnitude.

Similar to the RT results, a reverse Simon effect was found on error rates $\left[F(1,23)=26.9, M S_{\mathrm{e}}=0.02, p<\right.$ .001 ; see Figure 6B]. With left-hand responses, more errors were made with LVF presentations (3.6\%) than with RVF presentations (1.8\%), whereas with right-hand responses, more errors were made with stimuli in the RVF (3.9\%) than with stimuli in the LVF $(2.4 \%)$.
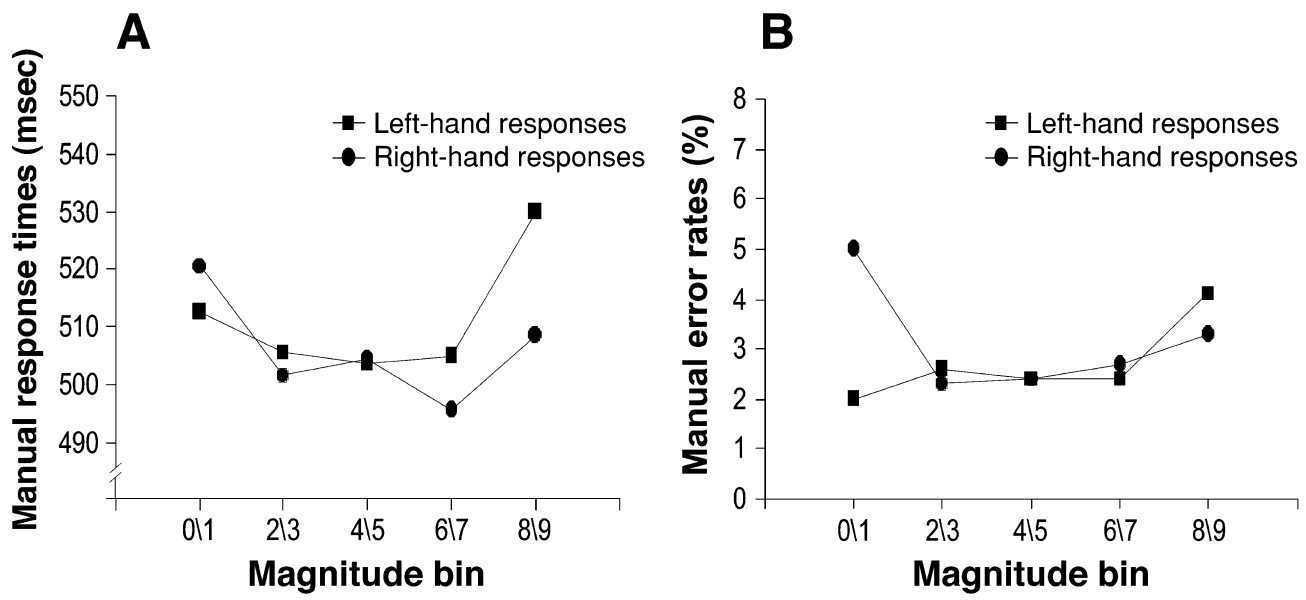

Figure 5. (A) Mean manual response times in the lateralized manual task of Experiment 2 for left-hand responses and right-hand responses as a function of numerical magnitude. (B) Manual error rates in the lateralized manual task of Experiment 2 for left-hand responses and right-hand responses as a function of numerical magnitude. 



\begin{abstract}
Figure 6. (A) Mean manual response times in the lateralized manual task of Experiment 2 for left-hand responses and right-hand responses as a function of side of presentation (left visual field vs. right visual field). (B) Manual error rates in the lateralized manual task of Experiment 2 for left-hand responses and right-hand responses as a function of side of presentation (left visual field vs. right visual field).
\end{abstract}

Comparisons between tasks. There was a significant main effect of stimulus presentation $[F(1,23)=49.98$, $\left.M S_{\mathrm{e}}=3,683.3, p<.001\right]$; responses to central stimuli were approximately $40 \mathrm{msec}$ faster than those to lateralized stimuli. There was also a significant main effect of effector $\left[F(1,23)=50.46, M S_{\mathrm{e}}=7,438.7, p<.001\right]$; vocal responses were about $55 \mathrm{msec}$ slower than manual responses. A significant effect of magnitude was also found $\left[F(4,92)=22.0, M S_{\mathrm{e}}=310.8, p<.001\right]$; RTs to the magnitude bins $0 / 1$ and $8 / 9$ were slower than those to the three intermediate bins. The interaction between magnitude and stimulus presentation was significant $\left[F(4,92)=8.33, M S_{\mathrm{e}}=107.0, p<.001\right]$, due to the fact that the difference in RT between central versus lateralized presentation was larger for the magnitude bin $8 / 9$ $(49 \mathrm{msec})$ than for all other magnitude bins (about $35 \mathrm{msec})$. Also, the interaction between magnitude and effector was significant $\left[F(4,92)=4.07, M S_{\mathrm{e}}=113.3\right.$, $p=.004]$, and the difference in RT between vocal and manual responses was larger for the magnitude bins $0 / 1$ $(61 \mathrm{msec})$ and $6 / 7(58 \mathrm{msec})$ than for the other magnitude bins (about $53 \mathrm{msec}$ ). All other two- and three-way interactions were not significant.

\section{Discussion}

The results of the lateralized vocal task replicated those of Experiment 1. Again, no SNARC-like effects were found, neither for RT nor for error rates, between magnitude and side of presentation with vocal responses and lateralized stimuli. In fact, Figures 1 and 2, showing the (nonsignificant) interaction effect between magnitude and side of presentation for Experiment 1 and for the lateralized vocal task in Experiment 2, are nearly identical. Also, in the lateralized manual task with manual responses and lateralized stimuli, no interaction between magnitude and side of presentation was found on
RT or on error rates. Given that the results found in Experiment 1 are replicated in Experiment 2, the explanation based on a lack of statistical power for the absence of the interaction between magnitude and side of presentation in Experiment 1 seems unlikely. Therefore, our results suggest that other features of Tlauka's (2002) Experiment 2 contributed to his finding of a significant interaction between magnitude and side of presentation.

In contrast, SNARC effects on RT and error rates were found between magnitude and response hand in the manual tasks. To further quantify the SNARC effect, we looked at its size effect in the two manual tasks. To this end, we regressed for each participant the difference between mean right-hand RT and mean left-hand RT on the 10 values of numerical magnitude (0-9; cf. Dehaene etal., 1993; Fias etal., 1996; Schwarz \& Keus, 2004), for each manual task separately. For each task, mean regression slopes were then calculated to obtain a measure of the size of the effect. One-sample $t$ tests showed that the mean regression slopes were significantly different from 0 ; for the central manual task, the mean regression slope was $-5.2[t(23)=-3.5, S E M=1.46, p=.002]$, and for the lateralized manual task, the mean regression slope was $-2.3[t(23)=-2.2, S E M=1.06, p=.041]$. A paired-samples $t$ test showed that the two mean regression slopes differed significantly from each other $[t(23)=$ 2.74, $S E M=1.04, p=.012]$. Second, to further explore the SNARC effect in the presence of lateralized stimuli, we analyzed the RTs in the lateralized manual task separately for compatible and incompatible trials. These analyses showed that the interaction between magnitude and response hand (the SNARC effect) was not found for compatible trials $\left[F(4,92)=1.54, M S_{\mathrm{e}}=1,297.8, p=\right.$ .197], but only for incompatible trials $[F(4,92)=6.76$, $\left.M S_{\mathrm{e}}=792.4, p<.001\right]$. This is in contrast to the results of Mapelli etal.'s (2003) Experiment2, in which no inter- 
action between the SNARC effect and the reverse Simon effect was found.

The results found in Experiment 2 are again evidence that seems hard to reconcile with the early hypothesis of the locus of the SNARC effect, which predicted SNARClike effects between magnitude and side of presentation, independent of the effector used to respond. Rather, the results favor the hypothesis that the locus of the SNARC effect is limited to a relatively late response-related processing stage, given that SNARC effects were found between magnitude and response hand, but not between magnitude and side of presentation. The fact that the SNARC effect in the lateralized manual task occurred only with the incompatible trials but not with compatible trials suggests that there was an interaction between the SNARC effect and the reverse Simon effect. This interaction implies that these effects occur at the same stage of processing (Sternberg, 1969); given that the (reverse) Simon effect is generally attributed to the responseselection stage (Lu \& Proctor, 1995; Mapelli etal., 2003; Simon \& Berbaum, 1990; Umiltà \& Nicoletti, 1990), this would imply that the SNARC effect occurs at the response-selection stage as well.

In addition to the SNARC effect, a reverse Simon effect was found showing that compatible trials (e.g., RVF presentation and right-hand response) were systematically slower and more error prone than incompatible trials (e.g., RVF presentation and left-hand response). One explanation for the reversal of the Simon effect in our experiment is suggested by the finding that the Simon effect seems to be due to a temporal overlap between the processing of the task-irrelevant and task-relevant information of the stimulus (Hommel, 1993, 1994, 1997; Roswarski \& Proctor, 1996; for related views, see also MacLeod, 1991; Schwarz \& Ischebeck, 2003). On the basis of the results in a number of Simon tasks in which he varied stimulus eccentricity, signal quality, signalbackground contrast and temporal buildup of the stimuli, Hommel (1993) reasoned that every experimental manipulation that increases the time interval between the formation of a mental representation of the irrelevant stimulus attribute (e.g., location) and the formation of a mental representation of the relevant stimulus attribute (e.g., color) decreases the temporal overlap between these two processes and should therefore produce smaller Simon effects.

Following Hommel's (1993) reasoning, Mapelli et al. (2003) hypothesized that the Simon effect could be reversed if the time interval between the processing of the task-irrelevant and the task-relevant attributes of the stimuli was made large enough. In an attempt to vary this time interval, they manipulated the eccentricity and size of the stimuli in their parity-judgment task. The results supported their expectations concerning the Simon effect: When the digits were presented $4^{\circ}$ into the LVF or RVF in font size 56, relatively fast RTs were obtained, and both a standard SNARC and a standard Simon effect were found (Experiment 1). When eccentricity was in- creased to $8^{\circ}$ and the font size was reduced to 28 to obtain longer RTs, a standard SNARC effect was still obtained, but now a reverse Simon effect was found (Experiment2).

If we relate Hommel's (1993) and Mapelli etal.'s (2003) results to our own findings, the reverse Simon effect in our lateralized manual task could be due to a fairly large time interval (i.e., small or no temporal overlap) between the processing of the irrelevant stimulus location and that of the relevant parity status. If this temporal-overlap view were correct, we should thus be able to manipulate the experimental conditions in the lateralized manual task in such a way that the temporal overlap between the processing of the relevant stimulus information and the stimulus location would increase enough to find a standard Simon effect. To test this prediction, we conducted a third experiment that was very similar to the lateralized manual task of Experiment 2, except that the task of the participant was to judge the digit's color instead of its parity status. This manipulation was based on the assumption that judging color is relatively fast in comparison with judging parity. If indeed this manipulation would shorten RTs and thus increase the temporal overlap between the processing of the irrelevant and relevant attributes of the stimulus, we would expect to find a smaller reverse or even a standard Simon effect in Experiment 3 .

\section{EXPERIMENT 3}

\section{Method}

Participants. Sixteen (15 female, 1 male) right-handed students at the University of Nijmegen, 18-26 years of age, participated in the experiment in return for a payment of $€ 5(\approx \$ 5)$ or course credit. None of them had participated in Experiment 1 or 2.

Stimuli and Apparatus. The stimuli and apparatus were the same as in the lateralized manual task of Experiment 2 except that stimuli were now presented in either saturated green or red.

Procedure. The task of the participants was to judge the color (green vs. red) of the presented digits. In the green-left (red-right) mapping, the participants were instructed to press the left button with their left index finger when the digit was presented in green and to press the right button with their right index finger when the digit was presented in red. In the red-left (green-right) mapping, the mapping of color to response side was reversed. Half of the participants performed the green-left mapping, and the other half performed the red-left mapping. The participants were instructed to be as quick and accurate as possible and to focus their gaze on the fixation cross during the entire trial.

Trials and blocks were built up in the same way as in the lateralized manual task, except that the stimuli were presented in either green or red. The color of the stimulus was systematically varied in such a way that each digit was presented in each color equally often (i.e., 30 times in each color).

The experiment took approximately $45 \mathrm{~min}$.

Data analyses. Trials with RTs shorter than $200 \mathrm{msec}$ or longer than $1,200 \mathrm{msec}(0.5 \%)$ were excluded from all analyses.

Mean RTs were calculated across all correct trials and were then subjected to a repeated measures $5 \times 2 \times 2 \times 2$ ANOVA with the four within-subjects factors magnitude bin $(0 / 1,2 / 3,4 / 5,6 / 7$, or $8 / 9$ ), parity (odd vs. even), side of presentation (LVF vs. RVF), and response hand (left vs. right). Note that in this experiment, the digit's parity status was irrelevant to the response, unlike in the previ- 
ous experiments. However, the factors magnitude bin and parity (see also Note 1) were chosen to be consistent with the analyses of the previous experiments.

Instead of parity, the color of the digit determined the response. Because the participants performed only one mapping of color to response hand (i.e., either the green-left or the red-left mapping), the factors color and response hand were confounded. Since the purpose of this experiment was to look at the interaction between side of presentation and response hand, we chose to use response hand instead of color in this analysis.

Error rates were calculated over all erroneous trials, then transformed as in Experiment 1 and were subjected to an ANOVA of the same format as that for RT.

\section{Results}

Response times. None of the four factors magnitude, parity, side of presentation, and response hand had a significant main effect on RT. Only two interactions were significant.

Most important to the purpose of this experiment, the interaction between side of presentation and response hand was found to be significant $\left[F(1,15)=32.42, M S_{\mathrm{e}}=\right.$ $3,246.2, p<.001]$. A standard Simon effect was found in that left-hand responses were faster to stimuli in the $\operatorname{LVF}(403 \mathrm{msec})$ than to those in the $\operatorname{RVF}(423 \mathrm{msec})$, whereas right-hand responses were faster to RVF presentations $(384 \mathrm{msec})$ than to LVF presentations $(415 \mathrm{msec}$; see Figure 7A).

Also, the interaction between magnitude and response hand was significant $\left[F(4,60)=3.41, M S_{\mathrm{e}}=564.7, p=\right.$ . 014]; the difference between right- and left-hand responses decreased with increasing magnitude. The size of this effect was quantified by a mean regression slope of $-1.03(S D=2.5)$. To further explore this SNARC effect, analyses on RT were done separately for compatible and incompatible trials. These analyses showed that an interaction between magnitude and response hand was not found for compatible trials $[F(4,60)=0.53$, $\left.M S_{\mathrm{e}}=866.8, p=.712\right]$, but only for incompatible trials $\left[F(4,60)=3.06, M S_{\mathrm{e}}=619.3, p=.023\right]$.

Error rates. The overall error rate was $2.35 \%$, and only two effects modulated it significantly. Response hand had a significant main effect on error rates $[F(1,15)=7.74$, $\left.M S_{\mathrm{e}}=0.011, p=.014\right]$; more errors were made with right- $(2.7 \%)$ than with left-hand responses $(2.0 \%)$.

As with RT, the interaction between side of presentation and response hand was significant $\left[F(1,15)=8.21, M S_{\mathrm{e}}=\right.$ $0.031, p=.012]$. With left-hand responses, fewer errors were made with LVF presentations (1.6\%) than with RVF presentations $(2.4 \%)$, whereas with right-hand responses, fewer errors were made with stimuli in the $\operatorname{RVF}(2.0 \%)$ than with stimuli in the $\operatorname{LVF}(3.4 \%$; see Figure 7B).

\section{Discussion}

The results of Experiment 3 showed a clear, robust standard Simon effect; in trials in which the side of presentation and the response hand (e.g., LVF and left-hand response) were compatible, responses were faster and more accurate than in trials in which they were incompatible (e.g., RVF and left-hand response). This was in contrast to the findings of the lateralized manual task in Experiment2, where we found exactly the opposite pattern. This difference in results between the two experiments can be explained by assuming that temporal overlap between processing of the irrelevant and relevant stimulus attributes plays a crucial role in the occurrence of the Simon effect. Hommel (1993) had suggested that experimental manipulations decreasing this temporal overlap would result in smaller or reverse Simon effects (see also Hommel, 1994, 1997; Mapelli et al., 2003; Roswarski \& Proctor, 1996). When applied to our findings, this suggests that, in color judgments, there should then be a relatively large temporal overlap between the
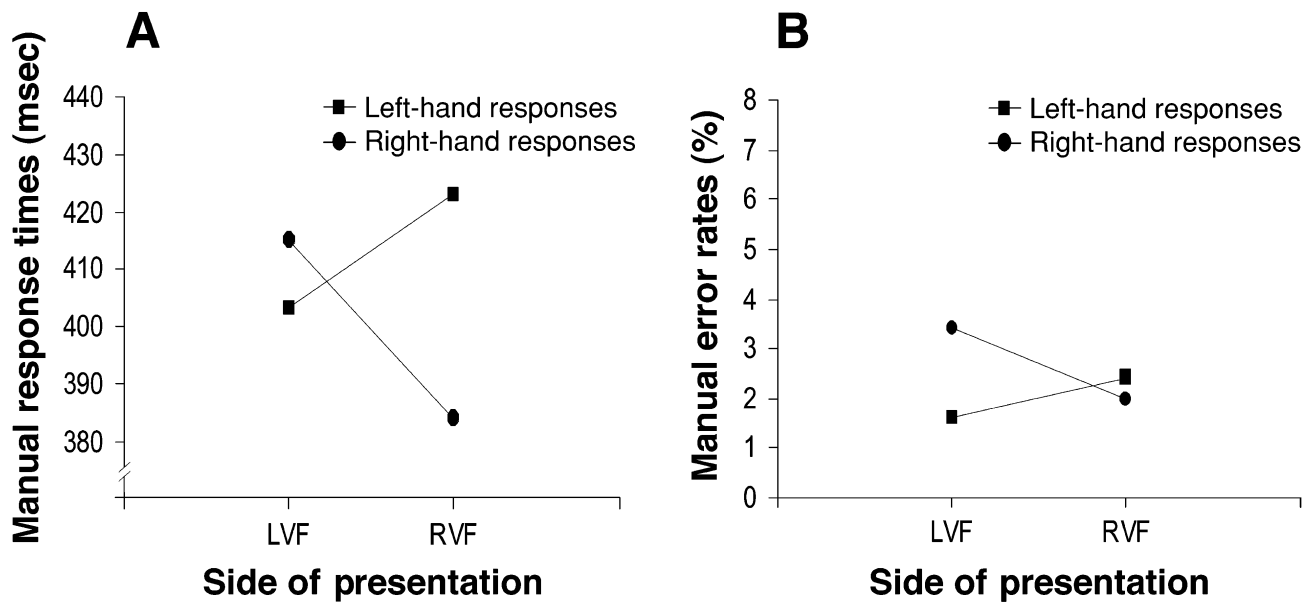

Figure 7. (A) Mean manual response times in Experiment 3 for left-hand responses and right-hand responses as a function of side of presentation (left visual field vs. right visual field). (B) Manual error rates in Experiment 3 for left-hand responses and right-hand responses as a function of side of presentation (left visual field vs. right visual field). 
processing of the location and the color of the stimulus, resulting in a standard Simon effect. On the other hand, in parity judgments, there seems to be a relatively smallor no-temporal overlap between the location and the parity status of the stimuli, which in turn resulted in a reverse Simon effect.

Another finding in the color task of Experiment 3 was a SNARC effect between magnitude and response hand, which, similar to the findings in Experiment2, occurred only for incompatible trials but not for compatible trials (but see Fias et al., 2001; Lammertyn et al., 2002). The broader implications of these findings will be discussed in the next section.

\section{GENERAL DISCUSSION}

Dehaene etal. (1993) were the first to report that in a parity-judgment task, responses to numerically small numbers are faster with the left hand than with the right hand, whereas those to numerically large numbers are faster with the right hand than with the left hand. This effect was labeled the SNARC effect, and in a number of subsequent studies it was shown that this effect was independent of the handedness of the participants, that it occurred with both digits and number words, and that it was also obtained with explicitly nonnumerical tasks (Dehaene etal., 1993; Fias, 2001; Fias etal., 1996).

In the present study, we have attempted to look into the functional origin(s) of the SNARC effect. Two possibilities were suggested, which are by no means mutually exclusive: a relatively early processing stage, during which an early space-related mental number representation of the presented digit is formed, and a later response selection stage, during which the initial space-related representation is mapped onto the available responses. The early-locus conceptualization predicted SNARClike effects at an early processing stage due to (in)congruencies between the side of presentation of the digit and the relative location of its internal representation on the mental number line, independent of response effectors. The late-locus conceptualization, on the other hand, predicts that the SNARC effect occurs due to (in)congruencies between the location of the mental representation of the digit on the mental number line and the response side, independent of the way in which the stimuli are presented to the participant. Most of the studies so far have provided conclusive evidence for a late responserelated origin of the SNARC effect, given that SNARC effects are typically reported in studies with centrally presented digits and manual responses (Dehaene et al., 1993; Fias, 2001; Fias et al., 1996; Schwarz \& Keus, 2004). However, these studies do not rule out the possibility of an additional early contribution to the SNARC effect, because all of them used central stimuli. To explore the possibility of such an additional early contribution to the SNARC effect, in this study we compared both central and lateralized stimuli and both manual and vocal responses.
In a parity judgment task with laterally presented digits and vocal responses (Experiment 1 and the lateralized vocal task of Experiment 2), no SNARC-like effects were found between numerical magnitude of the digits and side of presentation. Also with lateralized stimuli and manual responses (lateralized manual task of Experiment 2), no interaction was found between numerical magnitude and side of presentation. In other words, with both vocal and manual responses, the effect of side of presentation is not modulated by magnitude. On the other hand, with both central and lateralized stimuli and manual responses, SNARC effects were found between numerical magnitude and response hand. In both manual tasks of Experiment2, magnitude had a modulating effect on the difference between right- and left-hand responses.

Taken together, these results provide strong evidence that the SNARC effect originates only at a relatively late response-related processing stage. The absence of the magnitude $X$ side of presentation interaction suggests that the SNARC effect does not occur at a relatively early stimulus-related processing stage, but at a later responserelated stage. Furthermore, in the lateralized manual task of Experiment 2 and in the color task of Experiment 3 , SNARC effects were found, but only for trials in which side of presentation and side of response were incompatible. In contrast to the findings of Mapelli etal. (2003), our findings suggest an interaction between the SNARC and the (reverse) Simon effect, implying that these effects occur at the same stage of processing (Sternberg, 1969). Since the Simon effect is generally attributed to the response-selection stage (Lu \& Proctor, 1995; Mapelli et al., 2003; Simon \& Berbaum, 1990; Umiltà \& Nicoletti, 1990), this would imply that the SNARC effect occurs at the response-selection stage as well.

The absence of an additional early contribution to the SNARC effect in this study may be contrasted with previous findings (Fischer et al., 2003; Tlauka, 2002; see also Brysbaert, 1995) that could have been interpreted as suggesting an early, response-independent component of the SNARC effect. However, both studies differ from the typical tasks in which SNARC effects have been reported. Along with the present findings, this suggests that other nonstandard features of those studies, discussed in the introduction, are crucial in obtaining SNARC-like findings.

Another difference in results that warrants further study is the SNARC effect in our color task and its absence in the color tasks of Fias et al. (2001) and Lammertyn etal. (2002). Fias et al. (2001) argue that the SNARC effect was not found in tasks where color is the relevant feature, because color processing relies only minimally on parietal sources. This would result in too little neural overlap between the color and magnitude information (which are assumed to activate parietal areas) to elicit an observable interference of the relevant and irrelevant information. Given this explanation, it is surprising that we found a SNARC effect in a color task, in which the only difference with Fias et al.'s (2001) task 
was that the digits were now laterally instead of centrally presented. The difference in results cannot be attributed exclusively to lateralized stimulus presentation perse, since the SNARC effect was only found with incompatible trials in the color experiment, whereas the presentation was lateralized in all trials. Further research will be needed to explain the contradictory results concerning the SNARC effect in color tasks.

Another effect that was found in our experiments was the interaction between side of presentation and response hand. With the parity-judgment task of Experiment2, we found a reverse Simon effect in the sense that incompatible trials, in which side of presentation and side of response hand did not match, yielded faster RTs and fewer errors than did compatible trials. With the color judgment task in Experiment 3, compatible trials were faster and less error prone than incompatible trials (standard Simon effect). The opposite effects in the two experiments can be explained by suggesting that the temporal overlap between the processing of the task-irrelevant and task-relevant information of the stimulus plays a critical role in the occurrence of the Simon effect (Hommel, 1993; Mapelli et al., 2003). Apparently, when one is making color judgments, there is a relatively large temporal overlap between the processing of the irrelevant location and the relevant color of the stimulus, which results in a standard Simon effect. On the other hand, when one is making parity judgments, there seems to be little or no temporal overlap between the processing of the irrelevant location and the relevant parity status of the stimuli, which results in a reverse Simon effect.

The results of the present study suggest that the SNARC effect originates at a relatively late response-related stage - given the interaction between the SNARC effect and the reverse Simon effect, presumably at the response selection stage. One way to obtain further evidence for this view would be through the use of electroencephalographic measurements. More specifically, we expect that it should be possible to find a significant magnitude $X$ side of response interaction in the event-related potential (ERP) signal. If the SNARC effect does indeed originate at a response-related stage, this interaction should then correspond in time with the beginning of later response-related processing stages, as may be evidenced by the onset of the lateralized readiness potential (for details on the chronometric logic of ERP, see Dehaene, 1996, and Schwarz \& Heinze, 1998).

In conclusion, the results of the present experiments can be seen as strong evidence against any early-locus account of the SNARC effect, which assumes that the SNARC effect occurs in a relatively early processing stage. Rather, the results favor the hypothesis that the SNARC effect arises exclusively at a relatively late response-related processing stage (presumably response selection), most likely due to (in)congruencies between the digit's location on the mental number line and the side of the required response.

\section{REFERENCES}

Bächtold, D., Baumüller, M., \& Brugger, P. (1998). Stimulusresponse compatibility in representational space. Neuropsychologia, 36, 731-735.

Bishop, Y. M. M., Fienberg, S. E., \& Holland, P. W. (1975). Discrete multivariate analysis. Cambridge, MA: MIT Press.

Brysbaert, M. (1995). Arabic number reading: On the nature of the numerical scale and the origin of phonological recoding. Journal of Experimental Psychology: General, 124, 434-452.

BUTTERWORTH, B. (1999). The mathematical brain. London: Macmillan. CoHen, J. (1995). Statistical power analysis for the behavioral sciences (2nd ed.). Hillsdale, NJ: Erlbaum.

Craft, J. L., \& Simon, J. R. (1970). Processing symbolic information from a visual display: Interference from an irrelevant directional cue. Journal of Experimental Psychology, 83, 415-420.

DEHAENE, S. (1996). The organization of brain activations in number comparison: Event-related potentials and the additive-factors method. Journal of Cognitive Neuroscience, 8, 47-68.

DeHAENE, S. (1997). The number sense: How the mind creates mathematics. New York: Oxford University Press.

Dehaene, S., Bossini, S., \& Giraux, P. (1993). The mental representation of parity and number magnitude. Journal of Experimental Psychology: General, 122, 371-396.

Dehaene, S., Dehaene-Lambertz, G., \& Cohen, L. (1998). Abstract representations of numbers in the animal and human brain. Trends in Neurosciences, 21, 355-361.

FIAS, W. (2001). Two routes for the processing of verbal numbers: Evidence from the SNARC effect. Psychological Research, 65, 250-259.

Fias, W., Brysbaert, M., Geypens, F., \& D'Ydewalle, G. (1996). The importance of magnitude information in numerical processing: Evidence from the SNARC effect. Mathematical Cognition, 2, 95-110.

Fias, W., LAUWEREYNS, J., \& LAMmERTYN, J. (2001). Irrelevant digits affect feature-based attention depending on the overlap of neural circuits. Cognitive Brain Research, 12, 415-423.

Fischer, M. H., Castel, A. D., Dodd, M. D., \& Pratt, J. (2003). Perceiving numbers causes spatial shifts of attention. Nature Neuroscience, $\mathbf{6}, 555-556$.

HASBROUCQ, T., \& GUIARD, Y. (1991). Stimulus-response compatibility and the Simon effect: Towards a conceptual clarification. Journal of Experimental Psychology: Human Perception \& Performance, 17, 246-266.

HedGe, A., \& Marsh, N. W. A. (1975). The effect of irrelevant spatial correspondences on two-choice response-time. Acta Psychologica, 39, 427-439.

HoMmeL, B. (1993). The relationship between stimulus processing and response selection in the Simon task: Evidence for a temporal overlap. Psychological Research, 55, 280-290.

Hommel, B. (1994). Effects of irrelevant spatial S-R compatibility depend on stimulus complexity. Psychological Research, 56, 179-184.

Hommel, B. (1997). Interactions between stimulus-stimulus congruence and stimulus-response compatibility. Psychological Research, 59, 248-260.

Kornblum, S., HasbroucQ, T., \& Osman, A. (1990). Dimensional overlap: Cognitive basis for stimulus-response compatibility-A model and taxonomy. Psychological Review, 97, 253-270.

Lammertyn, J., Fias, W., \& LauWereyns, J. (2002). Semantic influences of feature-based attention due to overlap of neural circuits. Cortex, 38, 878-882.

LU, C. H., \& Proctor, R. W. (1995). The influence of irrelevant location information on performance: A review of the Simon and spatial Stroop effects. Psychonomic Bulletin \& Review, 2, 174-207.

MacLEOD, C. M. (1991). Half a century of research on the Stroop effect: An integrative review. Psychological Bulletin, 109, 163-203.

Mapelli, D., Rusconi, E., \& UMiltà, C. (2003). The SNARC effect: An instance of the Simon effect? Cognition, 88, B1-B10.

Palef, S. R., \& Olson, D. R. (1975). Spatial and verbal rivalry in a Stroop-like task. Canadian Journal of Psychology, 29, 201-209.

Restle, F. (1970). Speed of adding and comparing numbers. Journal of Experimental Psychology, 83, 274-278. 
Roswarski, T. E., \& Proctor, R. W. (1996). Multiple spatial codes and temporal overlap in choice-reaction tasks. Psychological Research, 59, 196-211.

SCHWARZ, W., \& HEINZE, H.-J. (1998). On the interaction of numerical and size information in digit comparison: A behavioral and eventrelated potential study. Neuropsychologia, 36, 1167-1179.

Schwarz, W., \& IschebecK, A. (2000). Sequential effects in number comparison. Journal of Experimental Psychology: Human Perception \& Performance, 26, 1606-1621.

SCHWARZ, W., \& IschEBECK, A. (2003). On the relative speed account of number-size interference in comparative judgments of numerals. Journal of Experimental Psychology: Human Perception \& Performance, 29, 507-522.

ScHWARZ, W., \& KeUS, I. M. (2004). Moving the eyes along the mental number line: Comparing SNARC effects with saccadic and manual responses. Perception \& Psychophysics, 66, 651-664.

Simon, J. R., \& BERBAUM, K. (1990). Effect of conflicting cues on information processing: The "Stroop effect" vs. the "Simon effect." Acta Psychologica, 73, 159-170.

SiMON, J. R., \& SMALL, A. M. (1969). Processing auditory information: Interference from an irrelevant cue. Journal of Applied Psychology, 53, 433-435.

STERNBERG, S. (1969). The discovery of processing stages: Extensions of Donders' method. Acta Psychologica, 30, 276-315.
TLAUKA, M. (2002). The processing of numbers in choice-reaction tasks. Australian Journal of Psychology, 54, 94-98.

Umiltà, C., \& NicOletTI, R. (1990). Spatial stimulus-response compatibility. In R. W. Proctor \& T. G. Reeve (Eds.), Stimulus-response compatibility: An integrated perspective (pp. 89-116). Amsterdam: North-Holland.

\section{NOTES}

1. The 10 digits are reduced into five magnitude bins because this allows for the orthogonal variation of magnitude and parity, which is impossible on the basis of individual digits (e.g., the digit 1 is never even). Also, in this way within any given bin, response times and error rates for left visual field and right visual field presentations are based on responses to both digits in a bin, which cancels out any main effect of individual digits.

2. The label "left-hand errors" refers to errors made when the correct response would have been with the left hand but the participant incorrectly responded with the right hand. Similarly, when making "righthand errors" the participant incorrectly responded with the left hand, when the correct response would have been with the right hand.

(Manuscript received October 1, 2003; revision accepted for publication July 23, 2004.) 